Basic nutritional investigation

\title{
A low-protein, high-carbohydrate diet increases browning in perirenal adipose tissue but not in inguinal adipose tissue
}

\author{
Mayara P. Pereira M.Sc ${ }^{a}$, Laís A.A. Ferreira ${ }^{a}$, Flávia H.S. da Silva ${ }^{\text {a }}$, \\ Marcelo A. Christoffolete Ph.D ${ }^{b}$, George S. Metsios Ph.D ${ }^{c}$, Valéria E. Chaves Ph.D ${ }^{d}$, \\ Suélem A. de França Ph.D ${ }^{\mathrm{a}}$, Amílcar S. Damazo Ph.D ${ }^{\mathrm{e}}$, Andreas D. Flouris Ph.D ${ }^{\mathrm{f}}$, \\ Nair H. Kawashita Ph.D ${ }^{\mathrm{a}, *}$ \\ a Department of Chemistry, Biochemistry Laboratory, Federal University of Mato Grosso, Cuiabá, Mato Grosso, Brazil \\ ${ }^{\mathrm{b}}$ Center of Natural and Human Sciences, Federal University of ABC, Santo André, São Paulo, Brazil \\ ${ }^{\mathrm{c}}$ Faculty of Education, Health and Wellbeing, Wolverhampton University, Walsall Campus, United Kingdom \\ ${ }^{\mathrm{d}}$ Laboratory of Physiology and Pharmacology, Federal University of São João Del Rei, Divinópolis, Minas Gerais, Brazil \\ e Department of Basic Health Sciences, Faculty of Medicine, Federal University of Mato Grosso, Cuiabá, Mato Grosso, Brazil \\ ${ }^{\mathrm{f}}$ FAME Laboratory, Department of exercise Science, University of Thessaly, Trikala, Greece
}

\section{A R T I C L E I N F O}

\section{Article history:}

Received 3 February 2017

Accepted 17 May 2017

\section{Keywords:}

Brite

Protein restriction

Energy expenditure

Low-protein

High-carbohydrate diet

White adipose tissue

\begin{abstract}
A B S T R A C T
Objective: The aim of this study was to evaluate the browning and origin of fatty acids (FAs) in the maintenance of triacylglycerol (TG) storage and/or as fuel for thermogenesis in perirenal adipose tissue (periWAT) and inguinal adipose tissue (ingWAT) of rats fed a low-protein, high-carbohydrate (LPHC) diet. Methods: LPHC (6\% protein, 74\% carbohydrate) or control (C; $17 \%$ protein, $63 \%$ carbohydrate) diets were administered to rats for $15 \mathrm{~d}$. The tissues were stained with hematoxylin and eosin for histologic analysis. The content of uncoupling protein 1 (UCP1) was determined by immunofluorescence. Levels of T-box transcription factor (TBX1), PR domain containing 16 (PRDM16), adipose triacylglycerol lipase (ATGL), hormone-sensitive lipase, lipoprotein lipase (LPL), glycerokinase, phosphoenolpyruvate carboxykinase (PEPCK), glucose transporter $4, \beta_{3}$-adrenergic receptor (AR), $\beta_{1}$-AR, protein kinase A (PKA), adenosine-monophosphate-activated protein kinase (AMPK), and phospho-AMPK were determined by immunoblotting. Serum fibroblast growth factor 21 (FGF21) was measured using a commercial kit (Student's $t$ tests, $P<0.05$ ).

Results: The LPHC diet increased FGF21 levels by 150 -fold. The presence of multilocular adipocytes, combined with the increased contents of UCP1, TBX1, and PRDM16 in periWAT of LPHC-fed rats, suggested the occurrence of browning. The contents of $\beta_{1}$-AR and LPL were increased in the periWAT. The ingWAT showed higher ATGL and PEPCK levels, phospho-AMPK/AMPK ratio, and reduced $\beta_{3}$-AR and PKA levels.

Conclusion: These findings suggest that browning occurred only in the periWAT and that higher utilization of FAs from blood lipoproteins acted as fuel for thermogenesis. Increased glycerol 3-phosphate generation by glyceroneogenesis increased FAs reesterification from lipolysis, explaining the increased TG storage in the ingWAT.
\end{abstract}

(c) 2017 Elsevier Inc. All rights reserved.
This work was supported by grants from Conselho Nacional de Desenvolvimento Científico e Tecnológico (CNPq grant no. 448070/2014-6) and Fundação de Amparo à Pesquisa do Estado de Mato Grosso (FAPEMAT grant no. 156547/2014) as well as the European Union 7th Framework Program (FP7-PEOPLE-2013-IRSES grant no. 612547).

* Corresponding author. Tel./fax: +55-65-3615-8765.

E-mail address: nairhonda@terra.com.br (N. H. Kawashita).

\section{Introduction}

The presence of multilocular adipocytes, which contain a greater number of mitochondria and express uncoupling protein 1 (UCP1), in white adipose tissue (WAT) was firstly reported in 1984 by Young et al. [1]. These "brown-like" adipocytes were termed brite or beige [2], and the process of differentiation to brite cells was called the browning process [3-8]. The browning process is 
normally increased in the context of cold stimulation in inguinal and perirenal white adipose tissue (ingWAT and periWAT, respectively) [8,9] and is rarely observed in epididymal WAT (epiWAT) [4]. UCP1 is located in the inner mitochondrial membrane, promoting proton leakage and uncoupling of the electron transport chain and oxidative phosphorylation in the mitochondrial respiratory chain. Thus, proton flux through ATP synthase is reduced, and some of the potential energy produced by the electrochemical proton gradient is dissipated as heat [10]. This uncoupling also increases the rate of electron transport in the mitochondrial respiratory chain and the consumption of oxygen and fatty acids (FAs) as FAs are the main fuel for thermogenesis [11]. For this reason, attempts to decrease overweightness and obesity have included strategies to increase energy expenditure by increasing in the number of brite cells [12].

We have been steadily focusing on the effects of administering a low-protein, high-carbohydrate (LPHC) diet to rats, introduced during the early phase of life [13-22] because children in occidental societies are often fed diets with these characteristics, introduced soon after weaning [23]. Fifteen days after introducing this diet, alterations in the energy balance occur, along with increased food intake and energy gain; these changes increase the amount of body lipids [13]. Adaptation to the LPHC diet increases plasma norepinephrine, epinephrine, corticosterone, tumor necrosis factor (TNF)- $\alpha$, leptin, and insulin sensitivity $[14,15,18]$. Additionally, the LPHC diet increases energy expenditure by increasing thermogenesis in the interscapular brown adipose tissue (iBAT), enhancing UCP1 content, and resulting in a higher response to adrenaline stimulation; this attenuates the energetic gains in these animals as they ingest $18 \%$ more calories than rats fed a control (C) diet [13]. Elucidation of major changes in the hormonal profiles and specific responses from these tissues have improved the understanding of the mechanisms involved in thermogenesis in iBAT and other alterations and processes in the adipose tissues, liver, and muscles of these animals [13-22].

To our knowledge, the effects of the LPHC diet on browning in the WAT have not yet been studied, although this issue is particularly interesting to researchers studying obesity control. Although many studies of browning have used cold as a stimulus, the main environmental factors triggering human obesity are a sedentary lifestyle and inadequate diet. Thus, the objective of this study was to investigate the development of brite cells in the periWAT and ingWAT and the origin of FAs in the maintenance of triacylglycerol (TG) storage, as fuel for thermogenesis, or both. Improving the understanding of these mechanisms and the effects of nutritional factors will contribute to the development of strategies for the prevention and treatment of human obesity [24].

\section{Materials and methods}

Animals and treatment

Male Wistar rats weighing approximately $100 \mathrm{~g}$ (30 to $32 \mathrm{~d}$ old) were randomized into either the $\mathrm{C}$ group or the LPHC group. Rats in the $\mathrm{C}$ group were fed a diet containing $17 \%$ protein, $63 \%$ carbohydrates, and $7 \%$ lipids [25], and those in the LPHC group were fed a diet containing 6\% protein, $74 \%$ carbohydrates, and $7 \%$ lipids for $15 \mathrm{~d}$. The diets were isocaloric $\left(16.3 \mathrm{~kJ} \cdot \mathrm{g}^{-1}\right)$, with the energy difference from the reduction in dietary protein compensated for by increasing the carbohydrate content [13-23,25] (Table 1). The rats were individually housed in metabolic cages in an environmentally controlled room (lights on from 0600 to 1800 ; temperature $22 \pm 1^{\circ} \mathrm{C}$ ). The experimental protocol was approved by the Ethics Committee of the Federal University of Mato Grosso. Samples for all determinations were obtained from rats in the fed state.

\section{Immunoblotting}

Segments of the WAT were coarsely minced and immediately homogenized in $50 \mathrm{mmol} \cdot \mathrm{L}^{-1}$ Tris- $\mathrm{HCl}$ buffer $\left(\mathrm{pH} 7.4 ; 4^{\circ} \mathrm{C}\right)$ containing $150 \mathrm{mmol} \cdot \mathrm{L}^{-1}$ sodium
Table 1

Composition $\left(\mathrm{g} \cdot \mathrm{kg}^{-1}\right)$ of the control (C) and low-protein, high-carbohydrate (LPHC) diets

\begin{tabular}{llc}
\hline Ingredient & Control diet & LPHC diet \\
\hline Casein (84\% protein) & 202 & 71.5 \\
Cornstarch & 397 & 480 \\
Dextrinized cornstarch & 130.5 & 159 \\
Sucrose & 100 & 121 \\
Soybean oil & 70 & 70 \\
Fiber (cellulose) & 50 & 50 \\
Mineral mix (AIN 93 G)* & 35 & 35 \\
Vitamin mix (AIN 93 G)* & 10 & 10 \\
L-cystine & 3 & 1 \\
Choline bitartrate & 2.5 & 2.5 \\
\hline
\end{tabular}

For detailed composition, see Reeves et al. [25].

chloride $(\mathrm{NaCl}), 1 \mathrm{mmol} \cdot \mathrm{L}^{-1}$ ethylenediaminetetraacetic acid, $1 \%$ Triton $\mathrm{X}-100,0.1 \%$ sodium dodecyl sulfate (SDS), $10 \mathrm{mmol} \cdot \mathrm{L}^{-1}$ sodium orthovanadate, $100 \mathrm{mmol} \cdot \mathrm{L}^{-1}$ sodium fluoride, $5 \mu \mathrm{g} \cdot \mathrm{mL}^{-1}$ of aprotinin, and $1 \mathrm{mmol} \cdot \mathrm{L}^{-1}$ phenylmethylsulfonyl fluoride. The homogenates were centrifuged at $10000 \mathrm{~g}$ for $40 \mathrm{~min}$ at $4{ }^{\circ} \mathrm{C}$, and the supernatant was used to determine the protein content [26], with bovine serum albumin (BSA) as the standard. Samples containing $100 \mu \mathrm{g}$ of protein from each experimental group were separated by SDS-polyacrylamide gel electrophoresis and transferred to nitrocellulose membranes. The levels of T-box transcription factor (TBX1), PR domain containing 16 (PRDM16), adipose triacylglycerol lipase (ATGL), hormone-sensitive lipase (HSL), lipoprotein lipase (LPL), glycerokinase (GyK), phosphoenolpyruvate carboxykinase (PEPCK), glucose transporter 4 (GLUT4), $\beta_{3}-$ adrenergic receptor (AR), $\beta_{1}$-AR, protein kinase A (PKA), adenosinemonophosphate-activated protein kinase (AMPK), and phospho-AMPK were detected after overnight incubation of the membrane at $4{ }^{\circ} \mathrm{C}$ with primary antibodies that had been diluted in TBS-T containing $5 \%$ dry albumin. $\alpha$-Tubulin was used as an internal control. The primary antibodies were detected using a peroxidase-conjugated secondary antibody and were then visualized with chemiluminescence reagents. The band intensities were quantified using ImageJ software (version 1.38), and the results are expressed as the relative ratio using the internal control as the baseline. Phospho-AMPK was expressed as the ratio relative to the level of total AMPK.

\section{Immunofluorescence}

Immunofluorescence was performed as described by Lemes da Silva et al. [27]. We used epiWAT as a negative control and iBAT as a positive control. Samples were incubated overnight in a fixative solution (4\% paraformaldehyde in $0.8 \mathrm{~mol} \cdot \mathrm{L}^{-1}$ phosphate buffer), followed by dehydration through a gradient of increasing ethanol concentrations. Samples were then clarified in xylene and embedded in paraffin. Samples were cut into $3-\mu$ m-thick sections using a HYRAXM60 microtome (Carl Zeiss, Germany), deparaffinized, and stained with hematoxylin and eosin. To determine UCP1 protein content, histologic sections were placed on slides with a biologic adhesive, deparaffinized, and incubated for $1 \mathrm{~h}$ at $70^{\circ} \mathrm{C}$ in $0.21 \%$ sodium citrate solution ( $\mathrm{pH} 6.0$ ). Samples were then incubated for 30 min with $3 \%$ hydrogen peroxide in $70 \%$ methanol to block endogenous peroxidase, permeabilized in $0.4 \%$ Tween 20 in phosphate-buffered saline (PBS) for $15 \mathrm{~min}$, and then blocked for $30 \mathrm{~min}$ with 5\% BSA (Sigma-Aldrich, Rio de Janeiro, Brazil) in PBS. Sections were then incubated with rabbit anti-UCP1 (Abcam, Inc., Cambridge, MA, USA; $1: 1000$ ) for $18 \mathrm{~h}$ at $4^{\circ} \mathrm{C}$ in a humidified chamber. Thereafter, sections were incubated with a goat antirabbit immunoglobulin G (IgG) secondary antibody conjugated to AlexaFluor 488 (Invitrogen, Eugene, OR, USA; 1:50). Antibodies were diluted with 1\% BSA in PBS. Sections also were stained with the nuclear fluorescent dye 4',6-diamidino-2-phenylindole (Sigma-Aldrich, St. Louis, MO, USA) to facilitate morphologic characterization. Finally, slices were washed in PBS, mounted in 1:1 glycerin:PBS, and examined under an AxioScope.A1 microscope (Carl Zeiss, Germany). We quantified UCP1 expression using AxioVision software (version 4.8.1, 2009), with values presented as median optical density in arbitrary units (AU; scale value range 0-255). For densitometry analysis, images were obtained with a $20 \times$ objective lens, and readings were reported as means \pm SEMs.

\section{Lipid content in the white adipose tissue}

The lipid content in the WAT was determined by gravimetric methods after extraction, according to the protocol published by Folch et al. [28]. The tissue aliquot (about $1 \mathrm{~g}$ ) was homogenized in chloroform-methanol (2:1), and the volume was brought to $10 \mathrm{~mL}$. After an overnight rest, the material was filtered, and $\mathrm{NaCl} 0.9 \%$ was added ( $20 \%$ of the volume after filtration). After slight shaking, the mixture was centrifuged. The superior aqueous phase was aspirated with a vacuum pump, and 
one aliquot of the chloroform phase $(\sim 3 \mathrm{~mL})$ was transferred to a preweighed vial. The material was evaporated until a constant weight was reached.

Determination of serum fibroblast growth factor 21 levels

Fibroblast growth factor (FGF21) levels were assessed in serum using a commercial FGF21 immunoassay (MF2100 Quantikine ELISA kit products; R\&D Systems, Minneapolis, MN, USA).

\section{Statistical analysis}

The data are presented as means \pm SEMs. Statistical analysis was performed using GraphPad Prism software (version 5.01). Independent samples $t$ tests was used to compare the data from the two groups, which were found to be normally distributed. Differences were considered statistically significantly at $P<0.05$.

\section{Results}

Rats receiving the LPHC diet had lower body weights at the end of $15 \mathrm{~d}$ of treatment ( $\sim 22 \% ; P<0.001$ ), and the mass of the ingWAT was $78 \%$ higher without any changes in periWAT mass when compared with those in rats fed the $C$ diet. The lipid content per gram of ingWAT and periWAT was similar between groups (Table 2).

In histologic and immunofluorescence analyses, we usedepiWAT as a negative control and iBAT as a positive control. The periWAT of LPHC diet-fed rats showed the presence of multilocular adipocytes (Fig. 1 ) and increased (176\%; $P=0.02$ ) UCP1 content (Fig. 2) when compared with that of $C$ diet-fed rats. There were no alterations in adipocytes or UCP1 contents in the ingWAT of LPHC diet-fed rats.

The levels of TBX1 and PRDM16 were increased by $128 \%$ $(P=0.01)$ and $110 \%(P=0.02)$, respectively, in the periWAT of LPHC diet-fed rats compared with that of $C$ diet-fed rats (Fig. 3). The contents of these proteins in the ingWAT were similar between groups.

Serum concentrations of FGF21 (Fig. 4) were increased $~ 150$ fold in LPHC diet-fed rats (C: $41.43 \pm 8.04 \mathrm{pg} \cdot \mathrm{mL}^{-1}$; LPHC: $\left.6346.00 \pm 574.70 \mathrm{pg} \cdot \mathrm{mL}^{-1} ; P<0.0001\right)$. The contents of $\beta_{3}-\mathrm{AR}$ and PKA were reduced by $50 \%$ in the ingWAT of LPHC diet-fed rats compared with that in $C$ diet-fed rats $(P=0.04)$, and $\beta_{1-}$ AR levels were similar between groups $(P>0.05$; Fig. 5$)$. In the periWAT, $\beta_{3}$-AR and PKA were similar between groups $(P>0.05)$, but $\beta_{1}$-AR levels were increased by $44 \%$ in LPHC diet-fed rats when compared with that in $C$ diet-fed rats $(P=0.02$; Fig. 5).

The LPHC diet induced an increase in ATGL contents by $~ 72 \%$ $(P=0.04)$; however, there were no changes in HSL or lipoprotein lipase (LPL) contents in the ingWAT $(P>0.05$; Fig. 6). In contrast, the LPHC diet induced an increase in LPL content in the periWAT by about $61 \%(P<0.009)$, without any changes in ATGL or HSL

Table 2

Initial and final body weight, relative mass, and lipid and protein contents in inguinal white adipose tissue (ingWAT) and perirenal white adipose tissue (periWAT) of rats fed a control (C) or low-protein, high-carbohydrate (LPHC) diet for $15 \mathrm{~d}$

\begin{tabular}{|c|c|c|}
\hline Variable & Control group & LPHC group \\
\hline Initial body weight, $\mathrm{g}$ & $91.99 \pm 1.67$ & $91.90 \pm 1.39$ \\
\hline Final body weight, $\mathrm{g}$ & $190.50 \pm 5.63$ & $148.50 \pm 5.75^{*}$ \\
\hline Weight of ingWAT, $\mathrm{g} \cdot 100 \mathrm{~g}^{-1}$ & $1.31 \pm 0.09$ & $2.33 \pm 0.10^{*}$ \\
\hline Weight of periWAT, $\mathrm{g} \cdot 100 \mathrm{~g}^{-1}$ & $0.115 \pm 0.011$ & $0.137 \pm 0.008$ \\
\hline Content of lipid in ingWAT, $g \cdot g$ tissue ${ }^{-1}$ & $0.54 \pm 0.05$ & $0.48 \pm 0.04$ \\
\hline Content of lipid in periWAT, g.g tissue ${ }^{-1}$ & $0.56 \pm 0.01$ & $0.53 \pm 0.02$ \\
\hline Content of protein in ingWAT, $\mu \mathrm{g} \cdot \mathrm{mL}^{-1}$ & $1.17 \pm 0.16$ & $1.05 \pm 0.16$ \\
\hline Content of protein in periWAT, $\mu \mathrm{g} \cdot \mathrm{mL}^{-1}$ & $1.02 \pm 0.06$ & $1.04 \pm 0.10$ \\
\hline
\end{tabular}

Data presented as the mean \pm standard error of the mean $(\mathrm{N}=5-12$ rats $)$

* $P<0.01$ versus control group (Student's $t$ test).
$(P>0.05$; Fig. 6). The LPHC diet induced a $131 \%$ increase in the level of PEPCK, a key enzyme involved in glyceroneogenesis, in the ingWAT $(P=0.004)$; however, no changes in the periWAT were observed ( $P>0.05$; Fig. 7). The levels of GLUT4 and GyK, which catalyzes the phosphorylation of glycerol to glycerol 3-phosphate (G3 P), were similar between LPHC and C diet-fed rats in both tissues $(P>0.05$; Fig. 7$)$.

Figure 8 shows AMPK and phospho-AMPK levels. No dietrelated changes were observed in AMPK contents in either tissue $(P>0.05)$; however, the LPHC diet induced a $51 \%$ increase $(P=0.01)$ and $62 \%$ reduction $(P=0.002)$ in the phospho-AMPK/AMPK ratio in the ingWAT and periWAT, respectively.

\section{Discussion}

We previously studied the energy balance in rats treated with an LPHC diet, and showed that these animals had higher energy intake, energy gain, and energy expenditure (data are shown in Supplementary Table 1) [13]. The increase in energy expenditure is interpreted as a consequence of diet-induced adaptive thermogenesis related to higher food intake associated, at least partly, with the increased activity of iBAT, the mechanisms of which we also investigated in previous studies [13,21].

The present study was designed to evaluate the development of brite cells in the periWAT and ingWAT and the origin of FAs in the maintenance of TG storage, as fuel for thermogenesis, or both, as the periWAT and ingWAT are the main tissues in which browning has been observed $[8,9]$. The presence of multilocular adipocytes and increased levels UCP1, TBX1, and PRMD16 in periWAT from LPHC diet-fed rats when compared with that of $\mathrm{C}$ diet-fed rats supported the hypothesis that the browning process was increased in this tissue. TBX1 is a member of the T-box family, which is expressed only in brite cells; TBX1 is not associated with cells of the myogenic lineage, including brown adipocytes [7,29]. Despite the morphologic similarities between brite and brown adipocytes, increased content of TBX1 protein triggers different gene expression profiles in brite cells than in classical brown adipocytes [29]. Furthermore, PRDM16 triggers the expression of genes involved in the synthesis of proteins associated with the characteristics of brown adipocytes [30-32]. Both beige and classical brown fat cells express PRDM16 [4]. The high levels of serum FGF21 observed in LPHC diet-fed rats were consistent with increased in brite cells in the periWAT. FGF21 is a member of the FGF family and is expressed in the liver, as well as other tissues, including the WAT, brown adipose tissue (BAT), skeletal muscle, and pancreatic $\beta$-cells $[33,34]$. This factor induces the browning process in the WAT $[8,35,36]$. Moreover, fasting $[37,38]$ and leucine restriction [39] are associated with high levels of FGF21 in the blood. Sousa-Coelho et al. [39] reported that male C57 BL/6 J mice consuming a diet lacking leucine showed increased blood FGF21 levels. We have previously shown that rats from the LPHC group have higher levels of nonessential amino acids (data are shown in Supplementary Table 2) [19] can be synthesized from glycolysis (pyruvate) and Krebs cycle (alpha ketoglutarate) intermediaries [19]. Additionally, other studies show that the protein synthesis in the soleus [19] and EDL muscles is reduced [22]. So, an important pathway that uses amino acids is inhibited in LPHC rats.

However, the levels of essential amino acids, including leucine, are reduced in the blood [19].

In contrast to our findings in periWAT, the LPHC diet did not induce significant changes in ingWAT adipocytes or in the contents of UCP1, TBX1, and PRMD16 in ingWAT signaling; thus, browning was not observed in this tissue. Previous studies using different stimuli have reported browning in the ingWAT 


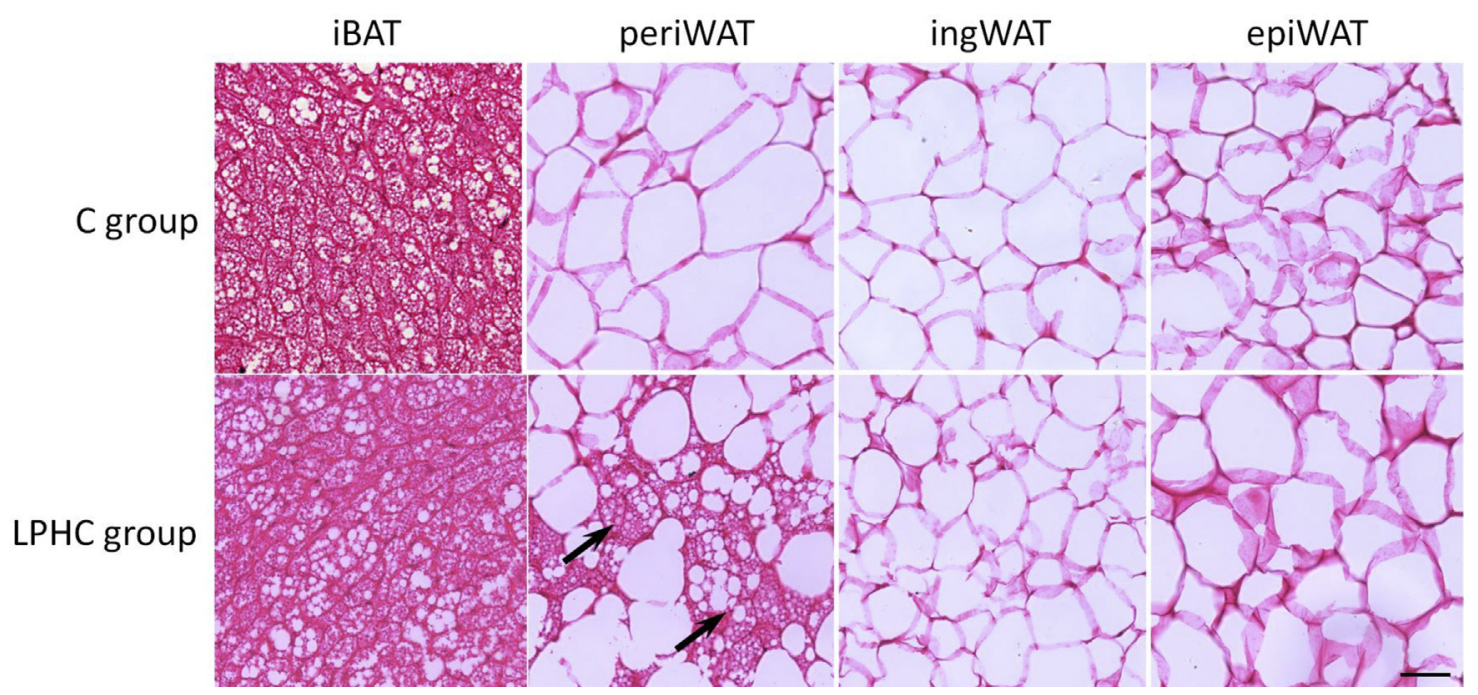

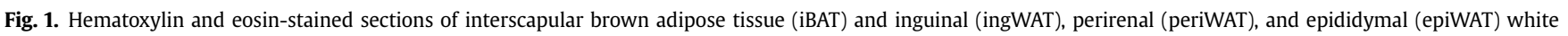

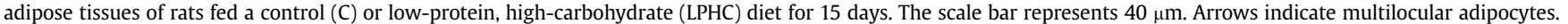

[8,35,40]. Véniant et al. [35] demonstrated that browning is stimulated by FGF21 when administered exogenously in lean but not obese mice at $21^{\circ} \mathrm{C}$ but not at $30^{\circ} \mathrm{C}$. These results showed that the effects of FGF21 on browning in the tissues depended on other stimuli; this could explain why the LPHC diet, despite increasing FGF21 levels and stimulating browning in the periWAT, did not result in generation of brite cells in the ingWAT.

We evaluated $\beta_{1}$-AR and $\beta_{3}$-AR contents in the ingWAT and periWAT since serum cathecolamines in LPHC diet-fed rats are higher than those in C diet-fed rats (data shown in Supplementary Table 3) [14] and adrenegic stimulation also is positively associated with brite cells $[8,40,41]$. In the periWAT of LPHC diet-fed rats, the content of $\beta_{3}$-AR did not change, whereas the content of $\beta_{1}$-AR was increased. In contrast, we observed the same $\beta_{1}$-AR content and a reduction in $\beta_{3}$-AR in the ingWAT when comparing corresponding tissues from $C$ diet-fed rats. The levels of PKA were reduced in the ingWAT and remained unchanged in the periWAT of LPHC diet-fed rats, confirming that the periWAT showed higher activation of the adrenergic system via $\beta$-AR. Thus, high levels of serum FGF21 and increased $\beta_{1}$-AR contents in the periWAT of LPHC diet-fed rats, regardless of whether there was a change in $\beta_{3}-A R$ or PKA, could stimulate the browning process.

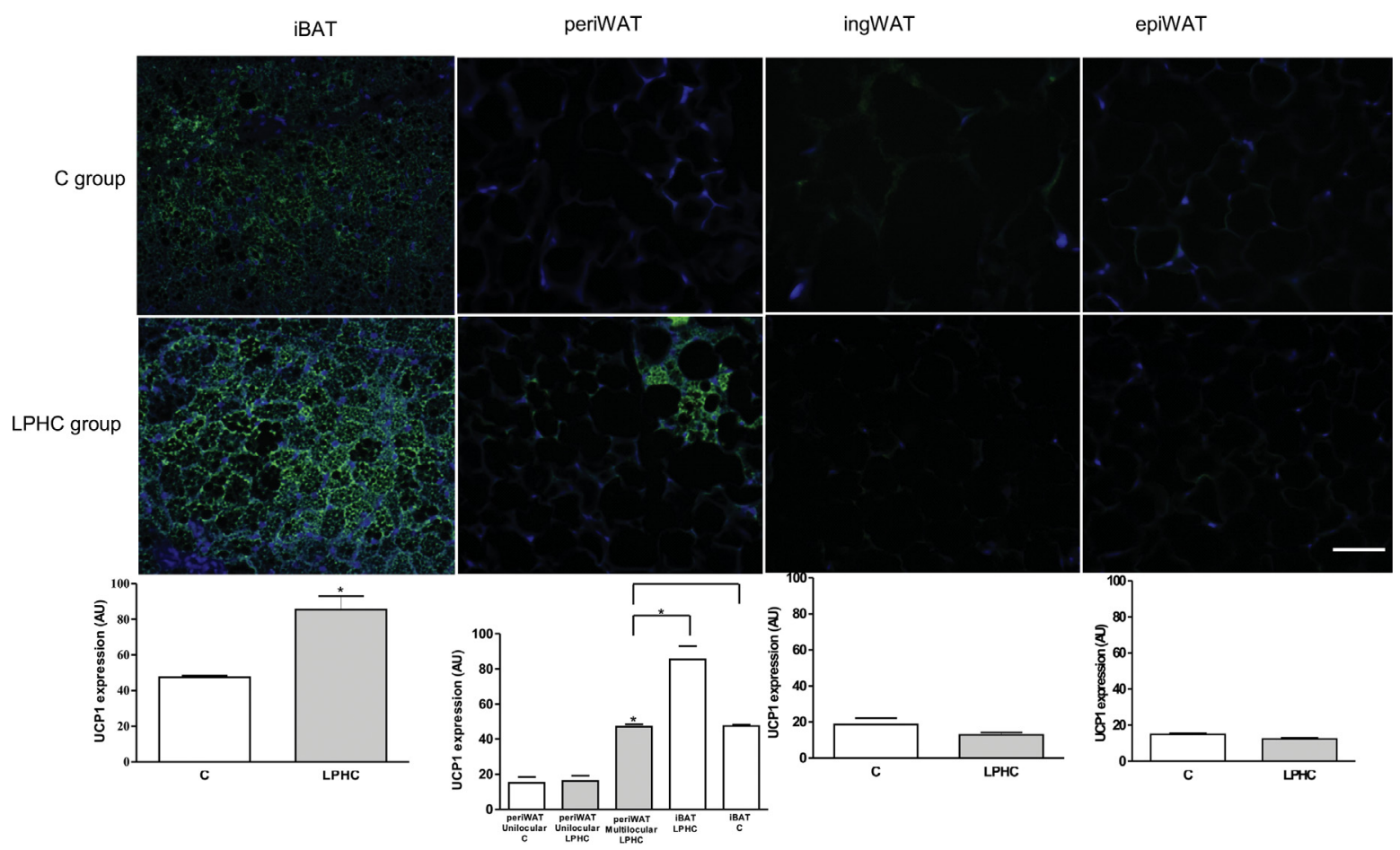

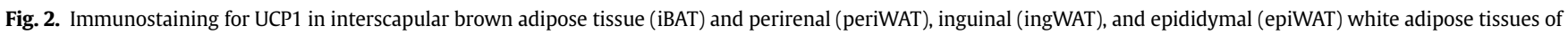

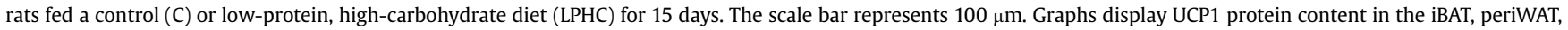

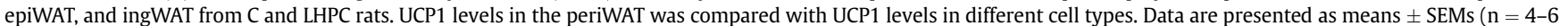
rats). ${ }^{*} P<0.05$ versus the control group (Student's $t$ test). 

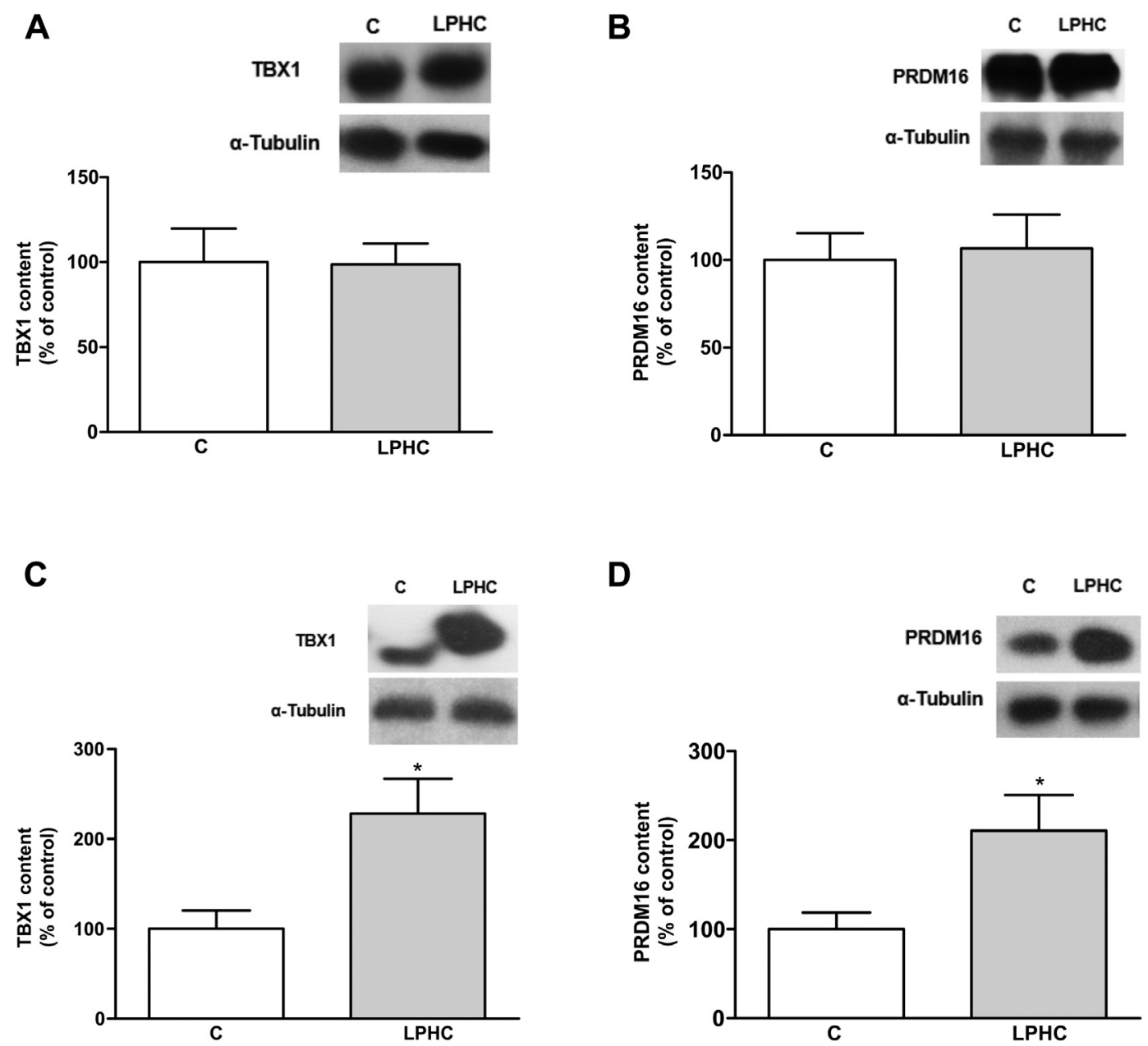

Fig. 3. Contents of T-box transcription factor (TBX1) and PR domain containing 16 (PRDM16) protein in the inguinal white adipose tissue (ingWAT) (A and B, respectively) and perirenal white adipose tissue (periWAT) (C and D, respectively) of rats fed a control (C) or low-protein, high-carbohydrate (LPHC) diet for 15 days. Data are presented as the means \pm SEMs ( $\mathrm{n}=5-8$ rats). ${ }^{*} \mathrm{P}<0.05$ versus the control group (Student's $t$ test).

Douris et al. [42] showed that central or peripheral FGF21 administration did not initiate browning in mice lacking $\beta$-AR, suggesting a relationship with the adrenergic system [42]. $\beta_{3}-\mathrm{AR}$ is thought to play a role in the browning process [43]; however, studies also have demonstrated that overexpression of $\beta_{1}$-AR in the WAT of mice induces the differentiation of brite adipocytes [44].

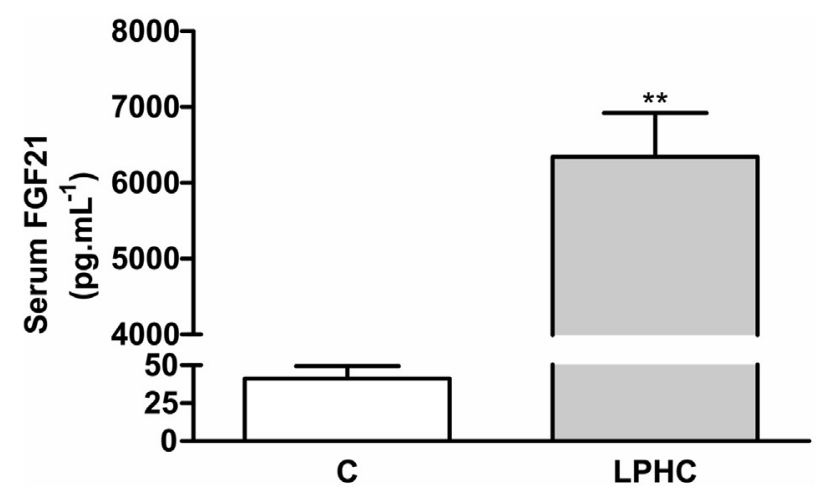

Fig. 4. Serum Fibroblast growth factor 21 (FGF21) level in rats fed a control (C) or low-protein, high-carbohydrate (LPHC) diet for 15 days. Data are presented as the means \pm SEMs ( $\mathrm{n}=6-8$ rats). ${ }^{* *} P<0.01$ versus the control group (Student's $t$ test).
Thus, our data show that the stimulation of the browning process in tissues does not depend solely on high serum levels of FGF21. In LPHC rats, the results suggest that differences in adrenergic stimulation may be one of the causes of the different responses observed in ingWAT and periWAT.

For evaluation of FAs generation for TG storage or thermogenesis, we determined the levels of the enzymes ATGL and HSL, which are involved in lipolysis, and for proteins in the G3 P generation pathway (GyK, PEPCK, and GLUT4). The phospho-AMPK/ AMPK ratio also was determined because of the importance of AMPK as a regulator of some of these proteins. The ingWAT from LPHC diet-fed rats showed a significant increase in relative mass and lipid contents, without evidence of browning. The increase in ATGL and the phospho-AMPK/AMPK ratio in the ingWAT of LPHC diet-fed rats suggested increased lipolysis in the tissue, although no changes were observed in HSL level. These enzymes act sequentially; although ATGL has a high affinity for TG, HSL has a high affinity for diacylglycerol (DAG) [16]. Studies have shown that the activity of ATGL is increased following phosphorylation at Ser406 by AMPK [45] and that depletion of AMPK promotes a reduction in the phosphorylation and activity of ATGL [46]. In contrast, HSL is activated by PKA-dependent phosphorylation. However, HSL phosphorylation at Ser565 by AMPK prevents phosphorylation at Ser563 and Ser660 by PKA [46]. Thus, the 
A

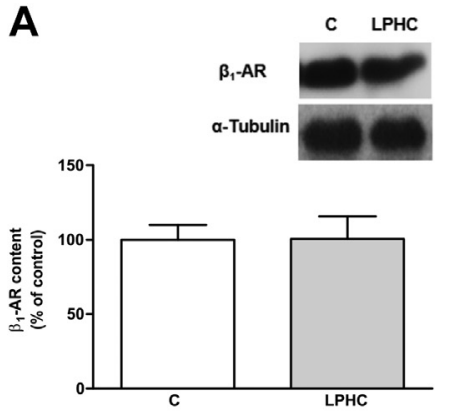

D
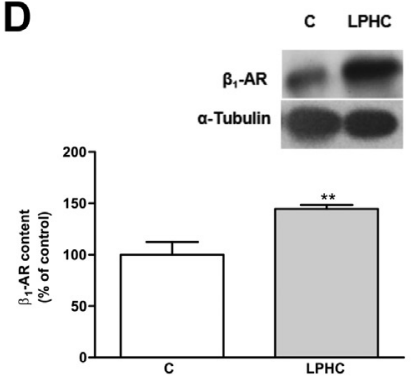

B

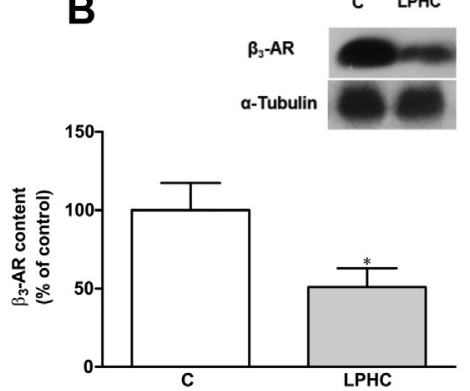

E

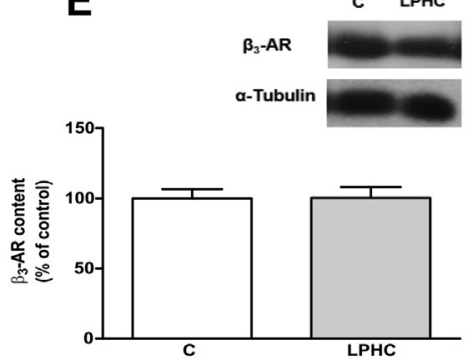

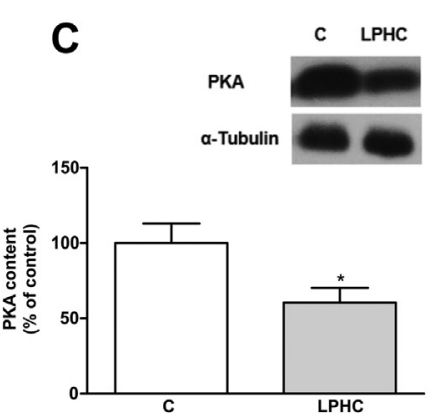

$\mathbf{F}$

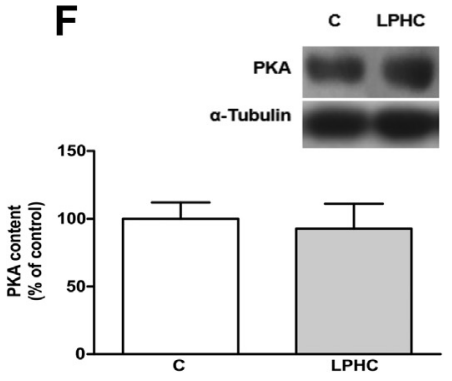

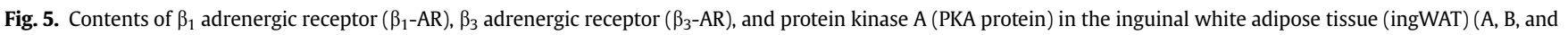

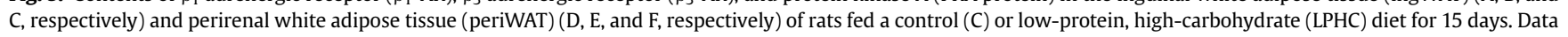
are presented as the means \pm SEMs $\left(\mathrm{n}=5-8\right.$ rats). ${ }^{*} P<0.05$ versus the control group; ${ }^{* *} P<0.01$ versus the control group (Student's $t$ test).

increased ratio of phospho to AMPK/AMPK suggested higher activity of ATGL and lower activity of HSL. The inhibition of HSL and simultaneous activation of ATGL by AMPK is a metabolic mechanism through which adipose cells preserve fat storage and maintain their main functions [46]. The increased PEPCK content observed in the ingWAT of LPHC diet-fed rats suggested an increase in the rate of G3 P generation by glyceroneogenesis, increasing the reesterification of FAs into TG [47]. The other proteins involved in G3 P synthesis (i.e., GyK and GLUT4) were not altered by the LPHC diet. As observed previously, the consumption of an LPHC diet induces increases in several substrates for glyceroneogesis, such as serum L-lactate, L-alanine, and L-glutamine [18] (data are shown in Supplementary Table 4) [18]. The levels of LPL in the ingWAT were similar in LPHC and C diet-fed rats, suggesting
A

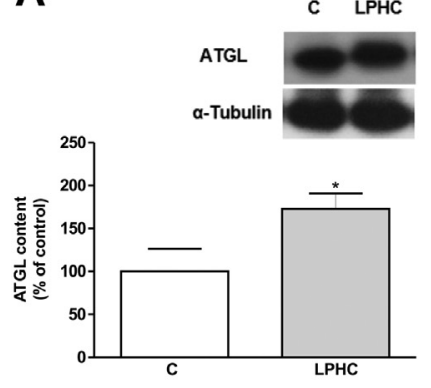

D

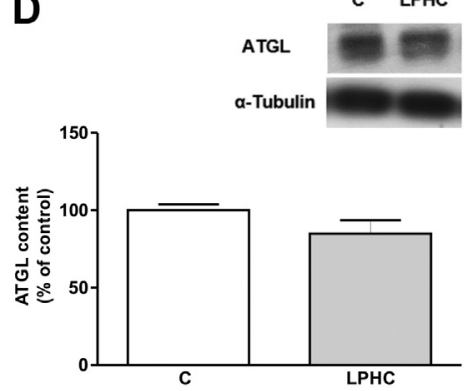

B

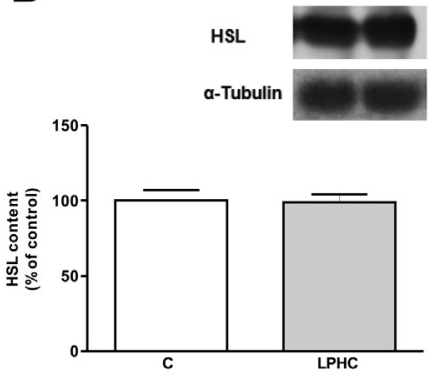

$\mathbf{E}$

C LPHC

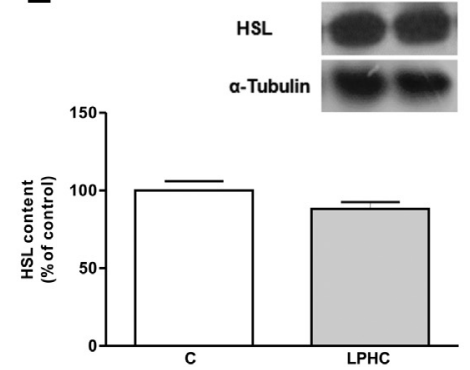

C c LPHC

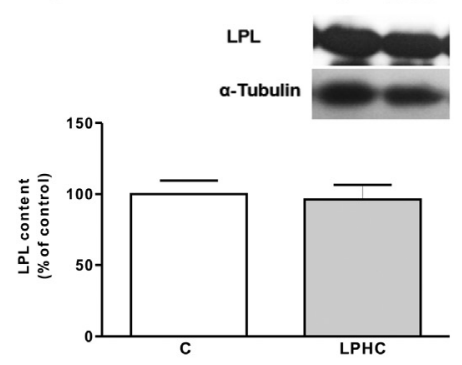

$\mathbf{F}$ C LPHC

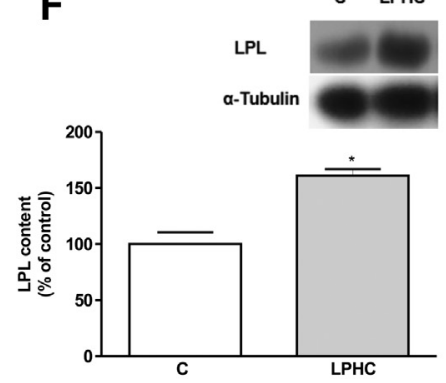

Fig. 6. Content of adipose triacylglycerol lipase (ATGL), hormone sensitive lipase (HSL), and lipoprotein lipase (LPL) protein in the inguinal white adipose tissue (ingWAT) (A, $\mathrm{B}$, and C, respectively) and perirenal white adipose tissue (periWAT) (D, E, and F, respectively) of rats fed a control (C) or low-protein, high-carbohydrate (LPHC) diet for 15 days. Data are presented as the means \pm SEMs ( $n=5-8$ rats). ${ }^{*} P<0.05$ versus the control group (Student's $t$ test). 


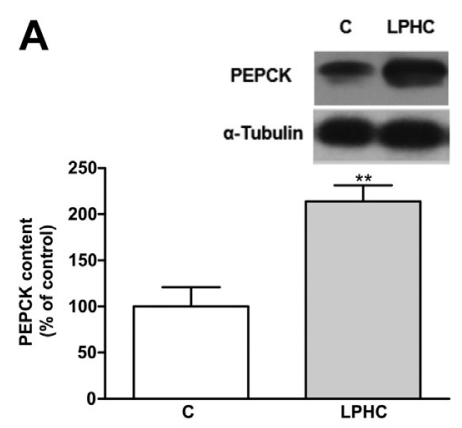

D

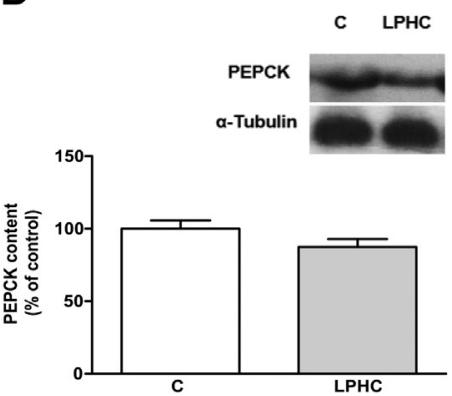

B

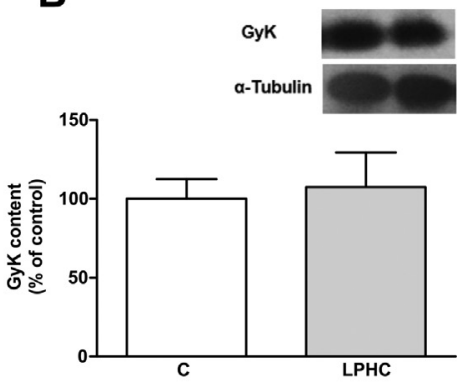

E

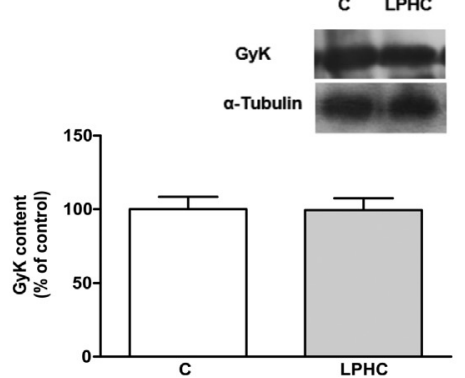

C C LPHC

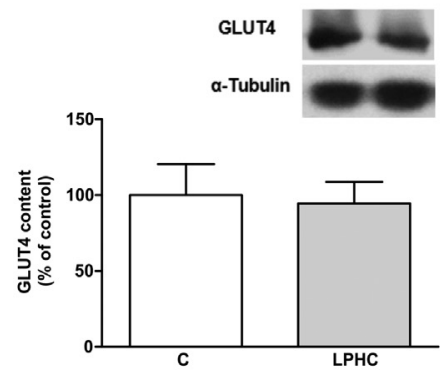

F

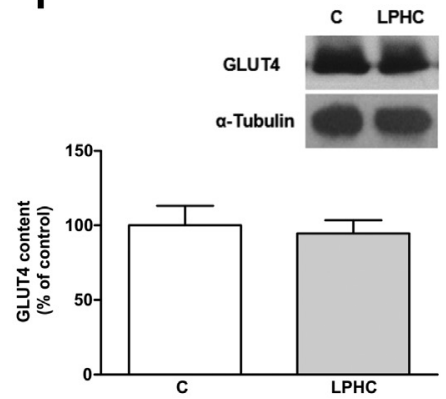

Fig. 7. Content of phosphoenolpyruvate carboxykinase (PEPCK), glycerokinase (GyK), and glucose transporter (GLUT4) proteins in the inguinal white adipose tissue (ingWAT) (A, B, and C, respectively) and perirenal white adipose tissue (periWAT) (D, E, and F, respectively) of rats fed a control (C) or low-protein, high-carbohydrate (LPHC) diet for 15 days. Data are presented as the means \pm SEMs $\left(\mathrm{n}=5-8\right.$ rats). ${ }^{* *} P<0.01$ versus the control group (Student's $t$ test).

A

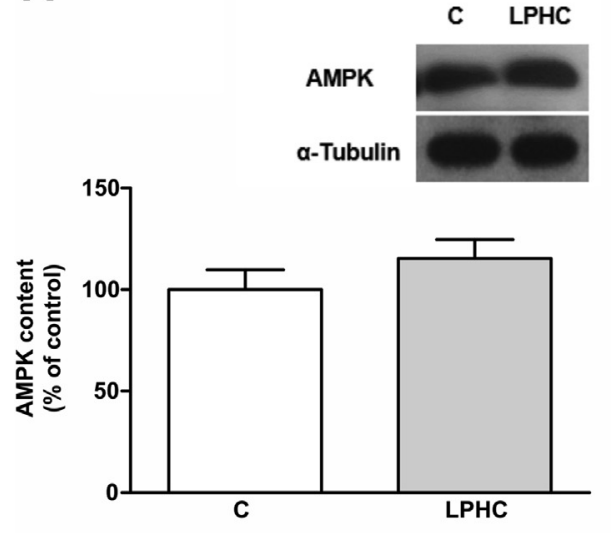

C

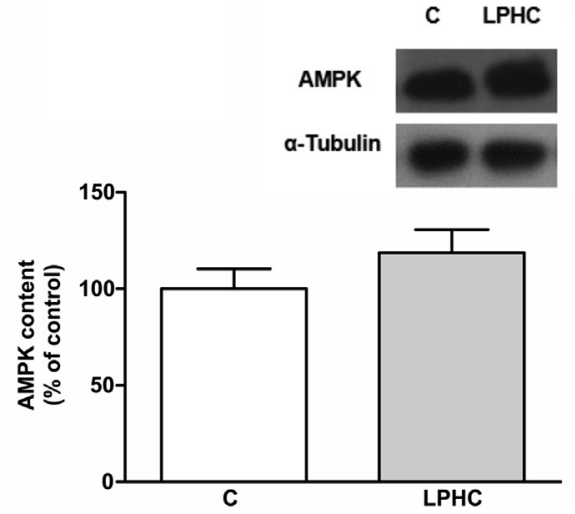

B

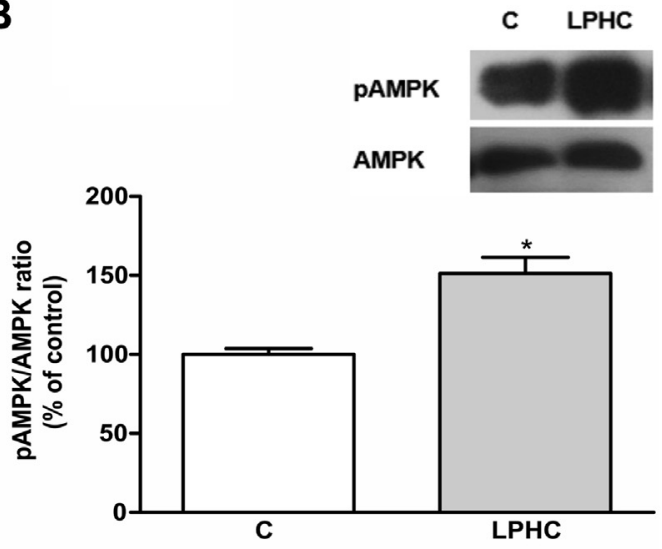

D

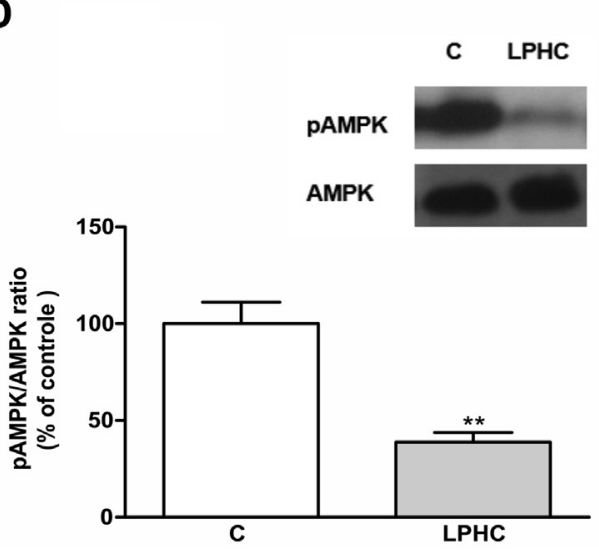

Fig. 8. Content of adenosine-monophosphate-activated protein kinase (AMPK) protein and pAMPK/AMPK ratio in inguinal white adipose tissue (ingWAT) (A and B, respectively) and in perirenal white adipose tissue (periWAT) (D and E, respectively) of rats fed a control (C) or a low-protein, high-carbohydrate (LPHC) diet for 15 days. Data are presented as the mean \pm SEM ( $\mathrm{n}=5-8$ rats). ${ }^{*} P<0.05$ vs. control group; ${ }^{* *} P<0.01$ vs. control group (Student's $t$ test). 
that the contributions of FAs uptake from blood lipoprotein were similar. These findings suggest that the higher relative mass of the ingWAT were due, at least in part, to higher reesterification of FAs from lipolysis with increases in G3 P content from glyceroneogenesis. Although the greater contribution of de novo FA synthesis could not be excluded, the high phospho-AMPK/AMPK ratio could signal the reduction of de novo FAs synthesis by inhibition of the acetyl-coenzyme (CoA) carboxylase enzyme [48,49].

In the periWAT from LPHC diet-fed rats, the mass and lipid contents in the tissues were maintained at levels similar to those in the periWAT from $C$ diet-fed rats, even with the additional use of FAs as a fuel for thermogenesis. The levels of ATGL and HSL also were similar between groups, accompanied by decreased phospho-AMPK/AMPK ratio. These findings suggested that the mechanism of activation of ATGL through the phospho-AMPK/ AMPK ratio in the periWAT could be reduced and the phosphorylation of HSL, induced by adrenergic stimuli, could be maintained at the same level as that in C diet-fed rats. These data indicated that alterations in the cycle of lipolysis-FA reesterification were not the source of additional FAs. However, the increase in LPL content induced by the LPHC diet suggested an increase in FAs uptake from circulating lipoproteins. Thus, these findings suggested that the additional FAs involved in thermogenesis in the periWAT of LPHC diet-fed rats were obtained from circulating lipoproteins.

The data set showing the browning process in periWAT suggests that this tissue contributes to the increase in energy expenditure in LPHC rats in conjunction with thermogenesis in iBAT. This may have important clinical implications because most studies on browning focus on cold despite that the main environmental factors triggering human obesity are a sedentary lifestyle and inadequate diet. The present findings that the LPHC diet leads to browning in the periWAT, increased thermogenesis, and attenuated body weight may suggest that when this diet is provided to newborns, it should be accompanied by instructions for increased food intake. In the ingWAT, where browning seems not to be stimulated, the FAs-TG cycle is increased. When FAs are converted into CoA derivatives and TG storage, and in another moment TG are hydrolyzed and the FAs oxidize, there is an energy loss of about $2 \%$ [50]. Although the loss of energy by this process can be limited, the adaptation to LPHC diet increases the energetic expenditure for actions in several tissues and for different thermogenic processes activated simultaneously.

\section{Conclusion}

The increase in FGF21 after administration of the LPHC diet was accompanied by an increase in the browning process in the periWAT, but not in the ingWAT, likely because of reduced adrenergic stimulation. The present data suggested that additional FAs for thermogenesis in the periWAT originate from circulating lipoprotein, whereas FAs involved in increased TG storage in the ingWAT originate from higher reesterification of FAs from lipolysis.

\section{Acknowledgments}

The authors acknowledge Celso Roberto Afonso and Air Francisco da Costa for their technical assistance.

\section{Supplementary data}

Supplementary data related to this article can be found at http://dx.doi.org/10.1016/j.nut.2017.05.007.

\section{References}

[1] Young P, Arch JR, Ashwell M. Brown adipose tissue in the parametrial fat pad of the mouse. FEBS Lett 1984;167:10-4.

[2] Beranger GE, Karbiener M, Barquissau V, Pisani DF, Scheideler M, Langin D, et al. In vitro brown and "brite"|"beige" adipogenesis: human cellular models and molecular aspects. Biochim Biophys Acta 2013;1831:905-14.

[3] Petrovic N, Walden TB, Shabalina IG, Timmons JA, Cannon B, Nedergaard J. Chronic peroxisome proliferator-activated receptor g (PPARg) activation of epididymally derived white adipocyte cultures reveals a population of thermogenically competent, UCP1-containing adipocytes molecularly distinct from classic brown adipocytes. J Biol Chem 2010;285:7153-64.

[4] Seale P, Conroe HM, Estall J, Kajimura S, Frontini A, Ishibashi J, et al. Prdm16 determines the thermogenic program of subcutaneous white adipose tissue in mice. J Clin Invest 2011;121:96-105.

[5] Gburcik V, Cawthorn WP, Nedergaard J, Timmons JA, Cannon B. An essential role for Tbx15 in the differentiation of brown and "brite" but not white adipocytes. Am J Physiol Endocrinol Metab 2012;303:E1053-60.

[6] Waldén TB, Hansen IR, Timmons JA, Cannon B, Nedergaard J. Recruited vs. nonrecruited molecular signatures of brown, "brite," and white adipose tissues. Am J Physiol Endocrinol Metab 2012;302:E19-31.

[7] Wu J, Boström P, Sparks LM, Ye L, Choi JH, Giang AH, et al. Beige adipocytes are a distinct type of thermogenic fat cell in mouse and human. Cell 2012;150:366-76.

[8] Fisher FM, Kleiner S, Douris N, Fox EC, Mepani RJ, Verdeguer F, et al. FGF21 regulates PGC- $1 \alpha$ and browning of white adipose tissues in adaptive thermogenesis. Genes Dev 2011;26:271-81.

[9] Basse A, Dixen K, Yadav R, Tygesen MP, Qvortrup K, Kristiansen K, et al Global gene expression profiling of brown to white adipose tissue transformation in sheep reveal novel transcriptional components linked to adipose remodeling. BMC Genomics 2016;16:215.

[10] Klaus S, Casteilla L, Bouillaud F, Ricquier D. The uncoupling protein UCP: A membranous mitochondrial ion carrier exclusively expressed in brown adipose tissue. Int J Biochem 1991;23:791-801.

[11] Nicholls DG, Locke RM. Thermogenic mechanisms in brown fat. Physiol Rev $1984 ; 64: 1-64$

[12] Forest C, Joffin N, Jaubert AM, Noirez P. What induces watts in WAT? Adipocyte 2016;5:136-52.

[13] Aparecida de França S, Pavani dos Santos M, Garófalo MAR, Navegantes LC Kettelhut IC, Lopes CF, et al. Low protein diet changes the energetic balance and sympathetic activity in brown adipose tissue of growing rats. Nutrition 2009;25:1186-92.

[14] Buzelle SL, Pavani dos Santos M, Baviera AM, Lopés CF, Garófalo MAR, Navegantes LCC, et al. A low-protein, high-carbohydrate diet increased the adipose lipid content without increasing the glycerol-3-phosphate or fatty acid content in growing rats. Can J Physiol Pharmacol 2010;88:1157-65.

[15] Pavani dos Santos M, Aparecida de França S, Santos JT, Bezelle SL, Bertolini GL, Garófalo MAR, et al. A low-protein, high-carbohydrate diet increases fatty acid uptake and reduces norepinephrine-induced lipolysis in rat retroperitoneal white adipose tissue. Lipids 2012;47:279-89.

[16] Feres DDS, Pavani dos Santos M, Buzelle SL, Pereira MP, Aparecida de França S, Garófalo MAR, et al. In vitro TNF- $\alpha$ - and noradrenaline-stimulated lipolysis is impaired in adipocytes from growing fed a low-protein, highcarbohydrate diet. Lipids 2013;48:779-86.

[17] Menezes AL, Pereira MP, Buzelle SL, Pavani Dos Santos P, França SA, Baviera AM, et al. A low-protein, high-carbohydrate diet increases de novo fatty acid synthesis from glycerol and glycerokinase content in the liver of growing rats. Nutr Res 2013;33:494-502.

[18] Pereira MP, Buzelle SL, Batistela E, Doneda DL, Aparecida de França S, Pavani dos Santos M, et al. High glucose uptake in growing rats adapted to a lowprotein, high-carbohydrate diet determines low fasting glycaemia even with high hepatic gluconeogenesis. Can J Physiol Pharmacol 2014;92:460-6.

[19] Batistela E, Pereira MP, Siqueira JT, Paula-Gomes S, Zanon NM, Oliveira EB, et al. Decreased rate of protein synthesis, caspase-3 activity, and ubiquitinproteasome proteolysis in soleus muscles from growing rats fed a lowprotein, high-carbohydrate diet. Can J Physiol Pharmacol 2014;92:445-54.

[20] Aparecida de França S, Pavani Dos Santos M, Nunes Queiroz da Costa RV, Froelich M, Buzelle SL, Chaves VE, et al. Low-protein, high-carbohydrate diet increases glucose uptake and fatty acid synthesis in brown adipose tissue of rats. Nutrition 2014;30:473-80.

[21] Aparecida de França S, Pavani Dos Santos M, Przygodda F, Garófalo MA Kettelhut IC, Magalhães DA, et al. A low-protein, high-carbohydrate diet stimulates thermogenesis in the brown adipose tissue of rats via ATP-2. Lipids 2016;51:303-10.

[22] Pavani dos Santos M, Batistela E, Pereira MP, Paula-Gomes S, Zanon NM Kettelhut IC, et al. Higher insulin sensitivity in EDL muscle of rats fed a lowprotein, high-carbohydrate diet inhibits the caspase-3 and ubiquitinproteasome proteolytic systems but does not increase protein synthesis. J Nutrit Biochem 2016;34:89-98.

[23] Ramalho AA, Mantovani SAS, Delfino BM, Pereira TM, Martins AC, OliartGuzmán $\mathrm{H}$, et al. Nutritional status of children under 5 years of age in the Brazilian Western Amazon before and after the interoceanic highway paving: a population-based study. BMC Public Health 2013;13:1098. 
[24] Feldeisen SE, Tucker KL. Nutritional strategies in the prevention and treatment of metabolic syndrome. Appl Physiol Nutr Metab 2007;32:46-60.

[25] Reeves PG, Nielsen FH, Fahey GC Jr. AIN-93 purified diets for laboratory rodents: Final report of the American Institute of Nutrition ad hoc writing committee on the reformulation of the AIN-76 A rodent diet. J Nutr 1993;123:1939-51.

[26] Bradford MM. A rapid and sensitive method for the quantitation of microgram quantities of protein utilizing the principle of protein-dye binding. Anal Biochem 1976;72:248-54.

[27] Lemes da Silva HA, Silva de Lima G, Boité MC, Porrozzi R, Hueb M, Damazo AS. Expression of annexin A1 in Leishmania-infected skin and its correlation with histopathological features. Rev Soc Bras Med Trop 2015;48:560-7.

[28] Folch J, Lees M, Sloane Stanley GH. A simple method for the isolation and purification of total lipids from animal tissues. J Biol Chem 1957;226:497-509.

[29] Okamatsu-Ogura Y, Fukano K, Tsubota A, Uozumi A, Terao A, Kimura K, et al. Thermogenic ability of uncoupling protein 1 in beige adipocytes in mice. PLoS One 2013;30:e84229.

[30] Kajimura S, Seale P, Tomaru T, Erdjument-Bromage H, Cooper MP, Ruas JL, et al. Regulation of the brown and white fat gene programs through a PRDM16/CtBP transcriptional complex. Genes Dev 2008;15:1397-409.

[31] Kajimura S, Seale P, Kubota K, Lunsford E, Frangioni JV, Gygi SP, et al. Initiation of myoblast to brown fat switch by a PRDM16-C/EBP- $\beta$ transcriptional complex. Nature 2009;460:1154-8.

[32] Christian M, Parker MG. The engineering of brown fat. J Mol Cell Biol $2010 ; 2: 23-5$.

[33] Hondares E, Iglesias R, Giralt A, Gonzalez FJ, Giralt M, Mapel T, et al. Thermogenic activation induces FGF21 expression and release in brown adipose tissue. J Biol Chem 2011;286:12983-90.

[34] Johnson CL, Weston JY, Sa Chadi, Fazio EN, Huff MW, Kharitonenkov A, et al. Fibroblast growth factor 21 reduces the severity of cerulean-induced pancreatilis in mice. Gastroenterology 2009;137:1795-804.

[35] Véniant MM, Sivits G, Helmering J, Komorowski R, Lee J, Fan W, et al. Pharmacologic effects of FGF21 are independent of the "browning" of white adipose tissue. Cell Metab 2015;21:731-8.

[36] Samms RJ, Smith DP, Cheng CC, Antonellis PP, Perfield JW 2nd, Kharitonenkov A, et al. Discrete aspects of FGF21 in vivo pharmacology do not require UCP1. Cell Rep 2015;11:991-9.

[37] Badman MK, Pissios P, Kennedy AR, Koukos G, Flier JS, Maratos-Flier E. Hepatic fibroblast growth factor 21 is regulates by PPAR $\alpha$ and is a key mediator of hepatic lipid metabolism in ketotic states. Cell Metab 2007;5:426-37.

[38] Vilá-Brau A, De Sousa-Coelho AN, Mayordomo C, Haro D, Marrero PF. Human HMGCS2 regulates mitochondrial fatty acid oxidation and FGF21 expression in HepH2 cell line. J Biol Chem 2011;286:20423-30.

[39] Sousa-Coelho AL, Marrero PF, Haro D. Activating transcription factor 4dependent induction of FGF21 during amino acid deprivation. Biochem J 2012;443:165-71.

[40] Berneda D, Frontini A, Cinti S, Christian M. Dynamic changes in lipid droplet-associated proteins in the "browning" of white adipose tissues. Biochem Biophys Acta 2013;1831:924-33.

[41] Nedergaard J, Cannon B. The browning of white adipose tissue: Some burning issues. Cell Metab 2014;20:396-407.

[42] Douris N, Stevanovic DM, Fisher FM, Cisu TI, Chee MJ, Nquyen NL, et al. Central fibroblast growth factor 21 browns white fate via sympathetic action on male mice. Endocrinology 2015;156:2470-81.

[43] Jimenez M, Barbatelli G, Allevi R, Cinti S, Seydoux J, Giacobino JP, et al. Beta 3-adrenoceptor knockout in C57BL/6J mice depresses the occurrence of brown adipocytes in white fat. Eur J Biochem 2003;270:699-705.

[44] Soloveva V, Graves AR, Rasenick MM, Spiegelman BM, Ross SR. Transgenic mice overexpressing the $\beta 1$-adrenergic receptor in adipose tissue are resistant to obesity. Mol Endocrinol 1997;11:27-38.

[45] Ahmadian M, Abbott MJ, Tang T, Hudak CSS, Kim Y, Bruss M, et al. Desnutrin/ATGL is regulated by AMPK and is required for a brown adipose phenotype. Cell Metab 2011;13:739-48.

[46] Kim SJ, Tang T, Abbott M, Viscarra JA, Wang Y, Sul HS. AMPK phosphorylates desnutrin/ATGL and hormone-sensitive lipase to regulate lipolysis and fatty acid oxidation within adipose tissue. Mol Cell Biol 2016;36:1961-76.

[47] Botion ML, Brito MN, Brito NA, Brito SR, Kettelhut IC, Migliorini RH. Glucose contribution to in vivo synthesis of glyceride-glycerol and fatty acids in rats adapted to a high-protein, carbohydrate-free diet. Metabolism 1998;47:1217-21.

[48] Park SH, Gammon SR, Knippers JD, Paulsen SR, Rubink DS, Winder WW. Phosphorylation-activiy relationships of AMPK and acetyl-CoA carboxylase in muscle. J Appl Physiol 2002;92:2475-82.

[49] Fediuc S, Gaidhu MP, Ceddia RB. Regulation of AMP-activated protein kinase and acetyl-CoA carboxylase phosphorylation by palmitate in skeletal muscle cells. J Lipid Res 2006;47:412-20.

[50] Feinman RD, Fine EJF. Thermodynamics and metabolic advantage of weight loss diets. Metab Syndr Relat Disord 2003;1:209-19. 